\title{
Contribuição metodológica em design de sinalização
}

\author{
Methodological contribution in signage design \\ Eduardo Cardoso, Fabiano de Vargas Scherer, Fábio Gonçalves Teixeira, Régio Pierre da \\ Silva, Tânia Luisa Koltermann da Silva
}

design, sinalização, metodologia de projeto

O presente artigo tem como objetivo apresentar a pesquisa sobre metodologia em design de sinalização realizada pelo Núcleo de Design Gráfico Ambiental - NDGA da Universidade Federal do Rio Grande do Sul. Pretende-se assim expor as metodologias utilizadas por autores relevantes nesta área como referência para a análise comparativa e posterior contribuição metodológica.

design, signage, design methodology

This article aims to present the research on signage design methodology performed by Center for Environmental Graphic Design - NDGA, Federal University of Rio Grande do Sul. The purpose is also set out the methodologies used by relevant authors in this area as a reference for comparative analysis and further methodological contribution.

\section{Introdução}

Novas especializações no campo do design surgiram, no decorrer do século $X X$, em resposta às mudanças culturais e econômicas que aconteceram na sociedade. Mais especificamente, o design gráfico, que trabalha com a informação, seja por meio da linguagem, da imagem ou dos símbolos, desdobrou-se em vários caminhos, entre os quais a sinalização. Esta, simplificadamente, busca fornecer a informação necessária ao usuário de um determinado espaço.

As fronteiras entre as disciplinas da arquitetura e do design gráfico, que interferem no espaço, foram claramente delineadas até que começaram a fundir-se em meados do século $\mathrm{XX}$, com influência de outros campos como o design de produto e o planejamento urbano. Esta fusão veio a ser chamada, posteriormente, de design gráfico ambiental, onde atualmente a sinalização se insere. Neste contexto, a arquitetura trabalha com a concepção do espaço e o design trabalha com a disponibilização da informação (HUNT, 2003). A qualidade de uma concepção interfere na qualidade da outra.

Segundo a Society for Environmental Graphic Design - SEGD (Sociedade de Design Gráfico Ambiental) dos Estados Unidos, dentro dos sistemas gráficos para ambientes, 0 processo de sinalização pode ser definido como o planejamento, projeto e especificação de elementos gráficos no ambiente construído ou natural. Estes elementos são usados para comunicar informações específicas em sistemas de identificação, informação, direção, interpretação, orientação, regulamentação e ambientação. De acordo com a ADG (2000), o design de sinalização procura otimizar, por vezes, até viabilizar, a utilização e o funcionamento de espaços, sejam eles abertos ou construídos.

Embora o termo sinalização possa ser considerado muito amplo e genérico, segundo Velho (2007), ao ir se modificando ao longo dos anos, ele reflete a complexidade ao incorporar novos atributos no seu desempenho (tais como o seu relacionamento com o ambiente, a introdução de uma linguagem gráfica mais expressiva e uma maior liberdade na escolha e no uso de tipografias, cores, com a introdução da informática). Nesse contexto, um projeto de sinalização pode ser caracterizado pelo resultado da combinação de vários seus subsistemas 
(informações, gráfico, físico/formal, construtivo, ambiental, de acessibilidade e segurança e normativo).

Neste artigo ressalta-se a questão da metodologia, neste caso, o estudo sobre o método. Para uma revisão dos métodos de projeto em sinalização, estuda-se a sua classificação e seus critérios de avaliação. Pois, com a evolução da complexidade do projeto de sinalização, um método capaz de abarcar as diferentes etapas e conduzir para o melhor resultado, se faz cada vez mais necessário. De acordo com Uebele (2007), os projetos de sinalização que fornecem um sistema gráfico completo e eficiente são capazes de dar lugar a uma identidade, transformar a natureza das áreas que eles ocupam, e, claro, fornecer orientação. Indo um pouco mais longe, os projetos que atendem os requisitos citados acima e demonstrem-se adequados em sua materialidade, embasados em conceitos sustentáveis e adequados as questões de acessibilidade, apresentam o que de melhor o campo do design pode oferecer.

\section{Objetivos}

A existência desses subsistemas e das funções mencionadas demonstra a complexidade de um projeto de sinalização e explica a necessidade de utilização de métodos que direcionem, balizem e avaliem as propostas. Nesse sentido, modelos de classificação para metodologia de design vêm sendo gerados com o intuito de padronizar os dados coletados, bem como de oferecer um acesso diferenciado a tais dados por meio de agrupamentos e classificações. Flusser (2007) coloca que o propósito do gesto da abstração é deduzir as circunstâncias, fixálas e utilizá-las como modelo de ações futuras. Assim, a partir das análises, propõe-se uma metodologia que abarque esta complexidade, contribuindo tanto no contexto acadêmico quanto profissional.

Desta forma, têm-se como objetivos da presente pesquisa:

- Pesquisar, caracterizar e descrever as metodologias utilizadas por autores relevantes na área de design de sinalização;

- Ilustrar cada metodologia pesquisada através de esquemas gráficos, ressaltando o fluxo do processo e as etapas envolvidas;

- Realizar análise sobre cada metodologia de acordo com o aporte teórico referente ao tema;

- Realizar análise comparativa entre os processos dos referidos autores para contribuição e aprimoramento da metodologia empregada pelo Núcleo de Design Gráfico Ambiental - NDGA/UFRGS;

\section{Conceitos gerais}

Para o estudo dos métodos empregados em projetos de sinalização, antes se faz necessário à abordagem dos conceitos de: sinalização, baseado no trabalho de Crosby, Fletcher e Forbes, (1970), Folis e Hammer (1979), Smitshuijzen (2007) e Uebele (2007); señalética, baseado em Costa (2009); wayfinding, baseado em Lynch (1997), Arthur e Passani (1992), Berger (2005), Calori (2007) e Gibson (2009); e design gráfico ambiental, baseado, por sua vez, em Hunt (2003) e Velho (2007), conforme o quadro 1. Assim como uma abordagem dos métodos aplicados.

Quadro 1: Resumo dos conceitos relativos aos termos empregados em projeto de sinalização.

\begin{tabular}{|r|l|}
\hline Sinalização & $\begin{array}{l}\text { Processo de veiculação de informações. É o principio de marcar ou sinalizar algo. Transmite } \\
\text { informação mediante uma disposição adequada de sinais, regulamentando o fluxo de pessoas e } \\
\text { vé́culos, preferencialmente antecipando a demanda. Produto de design utilizado para orientar, } \\
\text { informar e guiar os usuários. }\end{array}$ \\
\hline Señalética & $\begin{array}{l}\text { Sua finalidade é a informação imediata e inequívoca, direcionada a reação à mensagem. Não } \\
\text { impõe a atenção, não provoca impacto e nem recorre a atenção estética. }\end{array}$ \\
\hline Wayfinding & $\begin{array}{l}\text { Voltado ao movimento orientado, utiliza-se da aplicação dos recursos da sinalização para } \\
\text { orientar e auxiliar os usuários a chegarem em determinado destino com segurança, tornando a } \\
\text { experiência dos mesmos agradável. }\end{array}$ \\
\hline $\begin{array}{r}\text { Design } \\
\text { Gráfico }\end{array}$ & $\begin{array}{l}\text { Campo multidisciplinar que inclui o design gráfico, design de produto, arquitetura e paisagismo. } \\
\text { Abrange questões de identidade, sinalização e wayfinding em um determinado ambiente. }\end{array}$ \\
\hline
\end{tabular}


Löbach (2001) coloca que o design poderia ser deduzido como idéia, projeto ou plano para a solução de um problema, e o ato de design, então, seria dar corpo à idéia e transmiti-la aos a outros. Para Cross (1993 apud Vasconcelos, 2010), a metodologia de design é caracterizada pelo estudo de princípios, práticas e procedimentos de design, com o objetivo de aprimorar a prática, apresentando uma orientação fortemente voltada ao processo.

Modelos de classificação para metodologia de design vêm sendo gerados com o intuito de padronizar os dados coletados, bem como de oferecer um acesso diferenciado a tais dados por meio de agrupamentos e classificações. Neste ponto, pode-se utilizar o modelo de classificação proposto por Bonsiepe, Kellner e Poessnecker (1984), o qual gera quatro grupos definidos por ele como tipos de classificação de macroestrutura do processo projetual. Estes grupos levam em conta: a linearidade (acima à esquerda), a presença de feedback (acima à direita), a circularidade (abaixo à esquerda) e a flexibilidade entre etapas (abaixo à direita).

\section{Metodologia}

Para a análise dos métodos utilizados em projetos de sinalização, partiu-se dos estudos de Bonsiepe (1984) e lançou-se mão dos critérios de avaliação estabelecidos por Vasconcelos et al (2010): (i) atitude metodológica, (ii) estrutura das etapas, (iii) flexibilidades das etapas e (iv) presença, tipo ou ausência de feedback. A estes critérios foi acrescido um aspecto particular dos projetos de sinalização, a existência e o objetivo do manual e em que fase o manual entra no projeto. Outro aspecto analisado foi a existência e a função com que se aplicam mock-ups e protótipos ao longo do desenvolvimento do projeto. Após a análise foram desenvolvidos esquemas gráficos para representação de cada metodologia apresentada, assim como quadros comparativos.

Os métodos analisados neste estudo foram selecionados através da bibliografia sugerida pela SEGD, que oferecem uma visão norte-americana do processo. Além destes, foram selecionados outras bibliografias devido a sua importância histórica e por trazerem a visão europeia do processo. Em ordem cronológica de publicação têm-se os seguintes métodos:

- John Follis e Dave Hammer (Architectural Signing and Graphics - 1979)

- Per Mollerup (Wayshowing - 2005)

- Andreas Uebele (Signage System \& Information Graphics - 2007)

- Chris Calori (Signage and Wayfinding Design - 2007)

- Edo Smitshuijzen (Signage Design Manual - 2007)

- Joan Costa (Señalética - 2007)

- David Gibson (The Wayfinding Handbook - 2009)

Ao analisar os esquemas metodológicos apresentados, têm-se uma visão geral do processo conforme cada autor. Não obstante, é possível identificar tendências de tais esquemas quanto às classificações propostas, que possivelmente demonstram o melhor caminho a ser seguido no desenvolvimento de métodos e processos de design.

\section{Discussão e resultados}

A seguir apresentam-se a estruturação básica e análise dos métodos acima citados, assim como alguns dos seus respectivos esquemas gráficos para ilustração de suas metodologias.

Em um dos percussores estudos sobre sinalização - Architectural Signing and Graphics, John Follis e Dave Hammer (1979) colocam quatro fases no processo de organização e desenvolvimento de projetos de sinalização: Planejamento; Projeto; Documentação e Licitações; e Supervisão. Em uma análise de acordo com os critérios de avaliação colocados anteriormente, tem-se (i) atitude metodológica prescritiva aos especificar os passos a seguir e como fazê-lo, (ii) estrutura linear dividida em 4 etapas (Figuras 1a e 1b), (iii) flexibilidade das etapas descontínua, uma vez que dependendo da situação e aprovação pode-se retornar à etapas anteriores; e (iv) presença de feedback visto a possibilidade de descontinuidade entre as etapas. A avaliação final do projeto implantado e aprovação pelo cliente implicam também 
em feedback final. Quanto aos aspectos em particular, não apresenta o emprego de manual do sistema de sinalização nem execução de protótipos enquanto etapas ou ações sistematizadas no processo, porém apresenta relatórios parciais e de detalhamento.

Figura 1a: Metodologia de John Follis e Dave Hammer. Fonte: Adaptado de Follis e Hammer (1979).

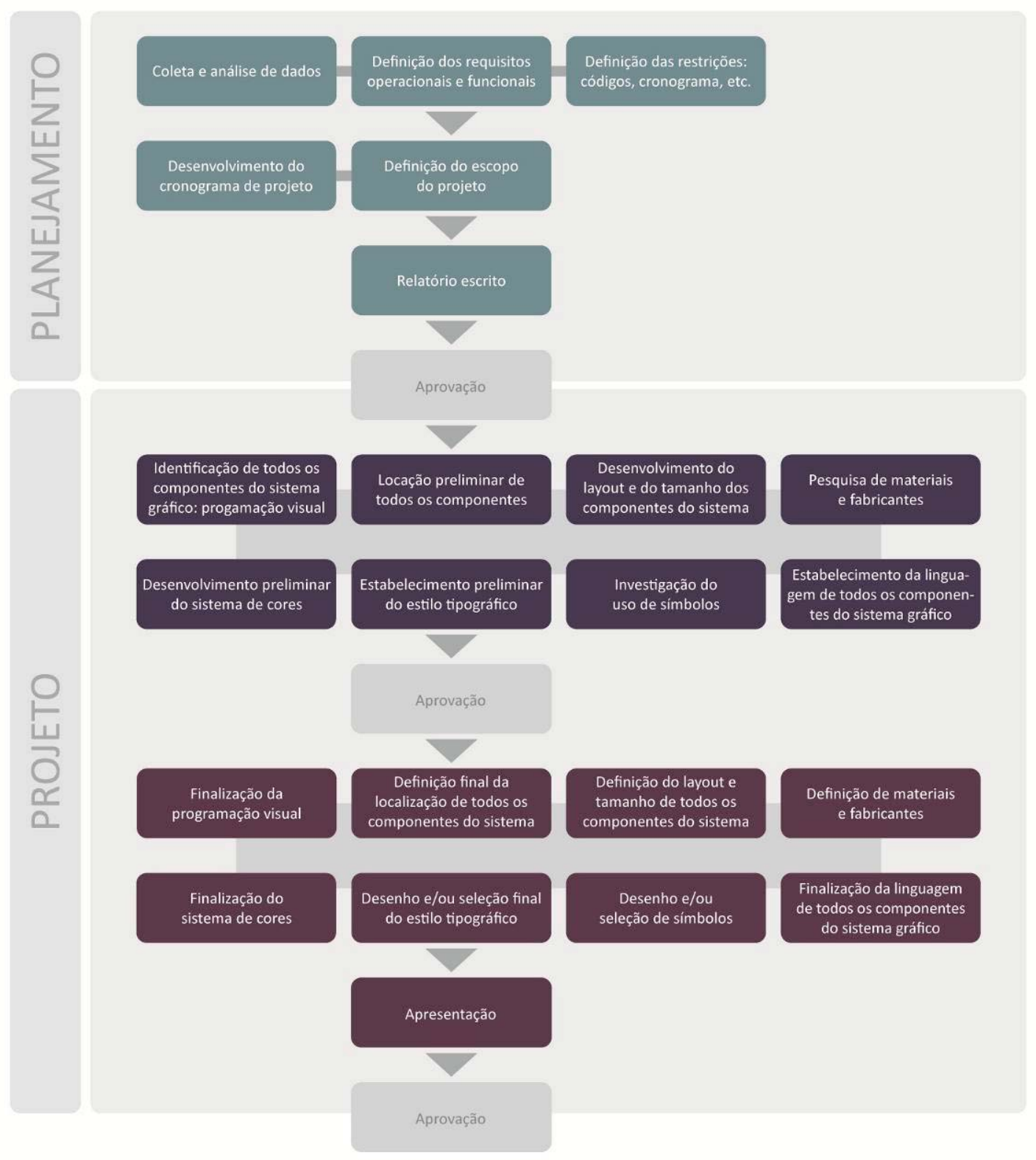


Figura 1b: Metodologia de John Follis e Dave Hammer. Fonte: Adaptado de Follis e Hammer (1979). Continuação do esquema anterior.

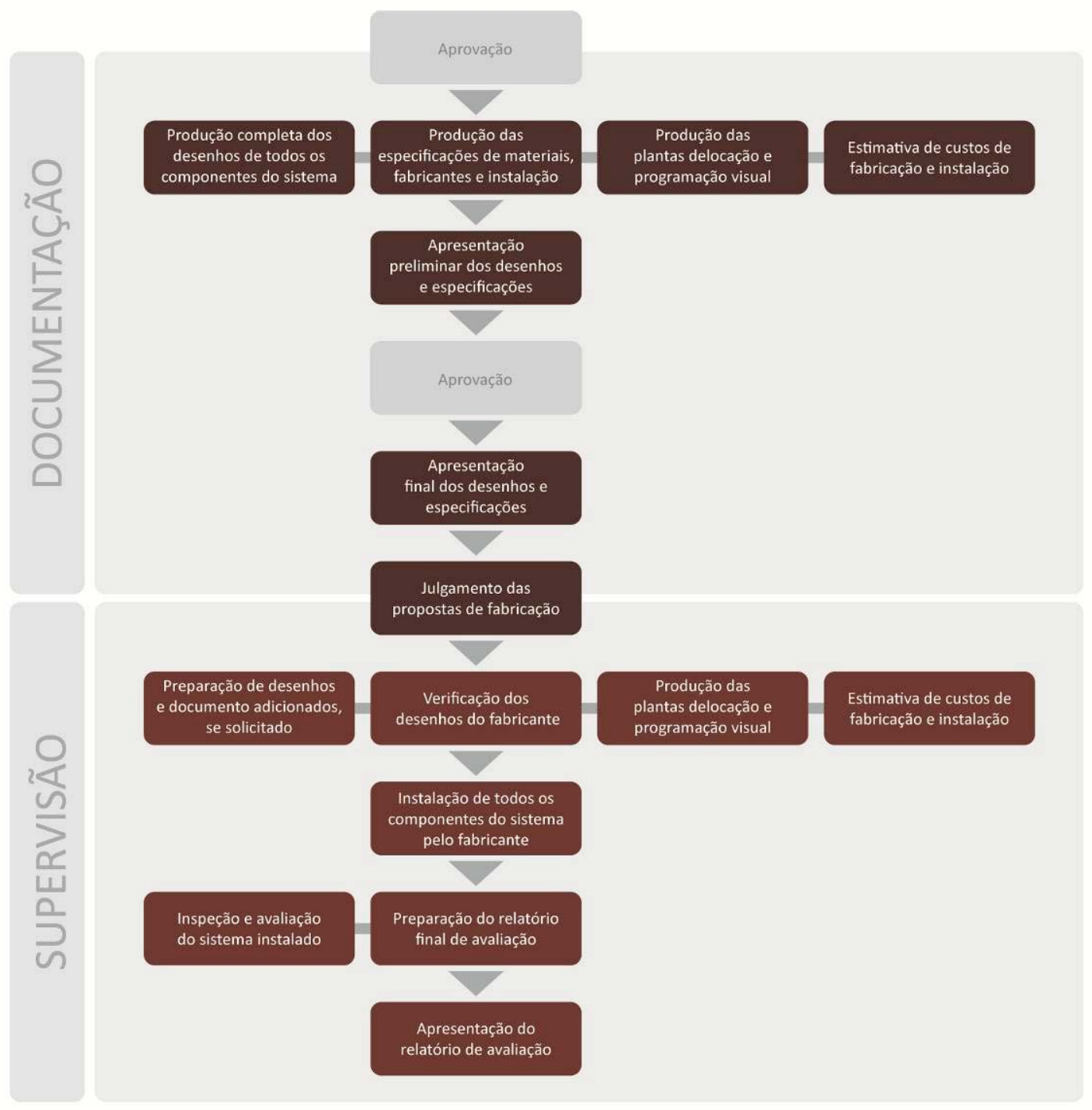

Para Mollerup (2005), no seu livro Wayshowing, o processo de projeto pode ser dividido em 10 fases, sendo que algumas podem ser subdivididas enquanto outras se mesclam quase não podendo distinguí-las. Esta ordem indica uma sequência lógica, porém não completamente linear, pois alguns passos incluem o retorno às etapas anteriores. $\mathrm{O}$ autor ainda apresenta sua metodologia dividindo cada etapa em ações a serem realizadas, questionamentos para sua efetiva realização e resultado final ou "saída". O processo tem início na fase denominada definição do problema e passa, consecutivamente, para composição da equipe, entrada de informação, análise de dados, planejamento estratégico, planejamento do sistema de sinalização, planejamento gráfico-visual, projeto de produto (projeto estrutural e físico dos elementos), implementação e, por fim, avaliação de resultados.

De acordo com os critérios de avaliação, tem-se (i) atitude metodológica prescritiva, (ii) estrutura das etapas de forma linear dividida em 10 etapas, (iii) flexibilidade descontínua, possibilitando retornar à etapas anteriores, porém em algumas etapas apenas; e (iv) presença de feedback conforme as figuras $2 \mathrm{a}$ e $2 \mathrm{~b}$. A avaliação final do projeto implantado e aprovação pelo cliente implicam também em feedback final. Quanto aos aspectos em particular, apresenta o emprego de manual do sistema de sinalização e execução de protótipos. 
Figura 2a: Metodologia de Peer Mollerup. Fonte: Adaptado de Mollerup (2005).




Figura 2b: Metodologia de Peer Mollerup. Fonte: Adaptado de Mollerup (2005). Continuação do esquema anterior.

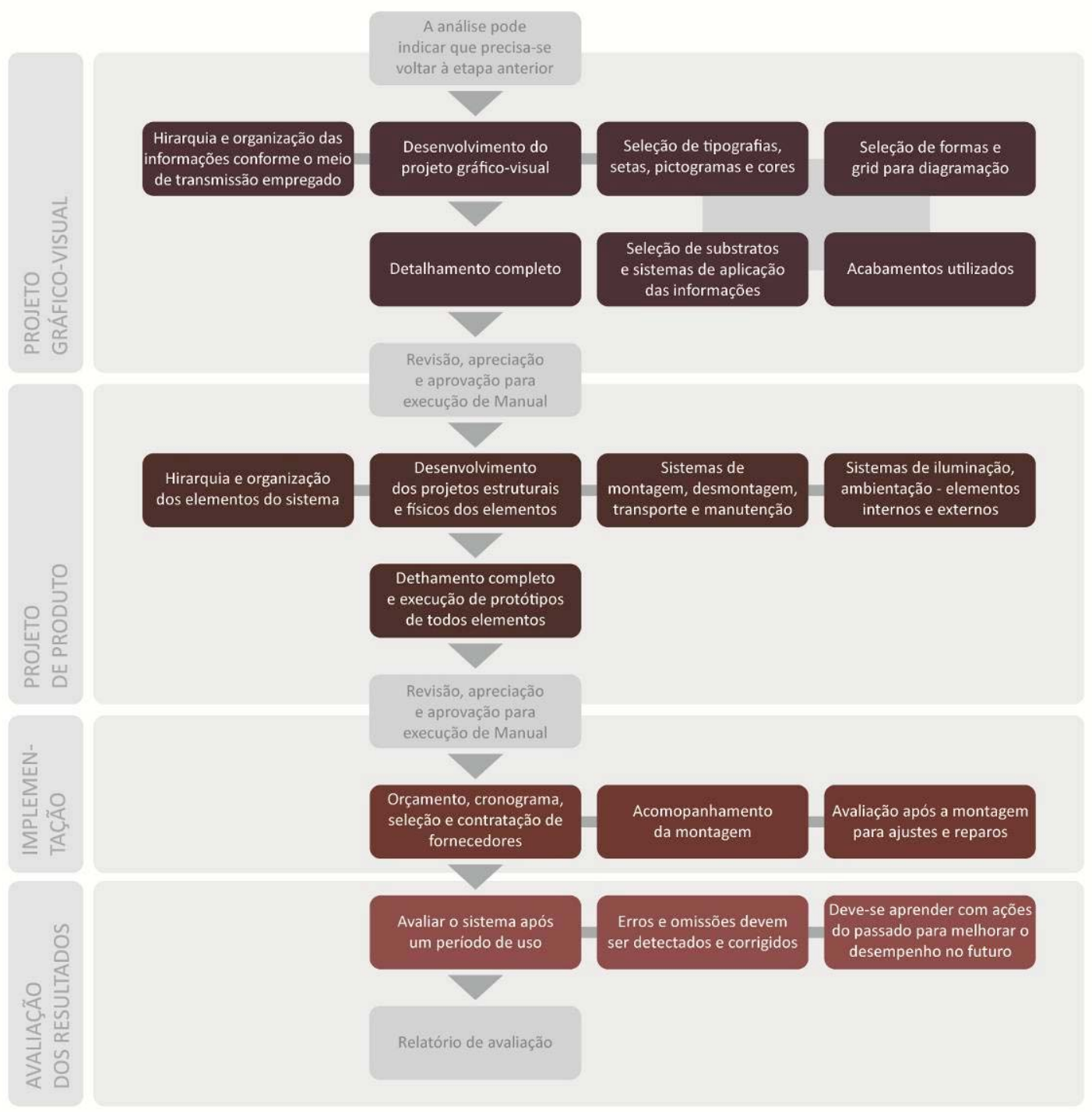

O livro Signage System \& Information Graphics de Uebele (2007) aborda a sinalização nas suas diferentes abrangências e traz informações desde a concepção gráfica do projeto, como tipografia, codificação de espaços, cores e malhas de diagramação até os detalhes de produção. São apresentados também alguns exemplos de projetos de sinalização para aeroportos, escolas e parques. Neste contexto, o autor propõe um guia para o processo de planejamento em dez passos (figuras $3 a$ e $3 b$ ), oferecendo alguma ajuda sobre a estruturação de um projeto: contrato; obtenção de informações; projeto preliminar; projeto; desenho, plano de trabalho e protótipos; especificações e orçamentos; propostas e contratos; entrega das especificações; supervisão da implantação; e conclusão.

De acordo com a avaliação, tem-se (i) atitude metodológica prescritiva, (ii) estrutura das etapas de forma linear dividida em 10 etapas, (iii) flexibilidade descontínua, dependendo da aprovação em certas etapas; e (iv) presença de feedback, visto a possibilidade de descontinuidade entre as etapas dependendo da aprovação pelo cliente. As avaliações consideram não só a aprovação pelo cliente, mas também pelos usuários e arquiteto responsável pelo projeto. Assim sendo, a avaliação final e as aprovações implicam em feedback final. Quanto aos aspectos em particular, apresenta relatório de documentos finais como memória do projeto, semelhante ao manual do sistema de sinalização. Apresenta ainda o uso de mock-ups e protótipos em vários momentos do processo como estudo e/ou validação das propostas. 
Figura 3a: Metodologia de Uebele. Fonte: Adaptado de Uebele (2007).

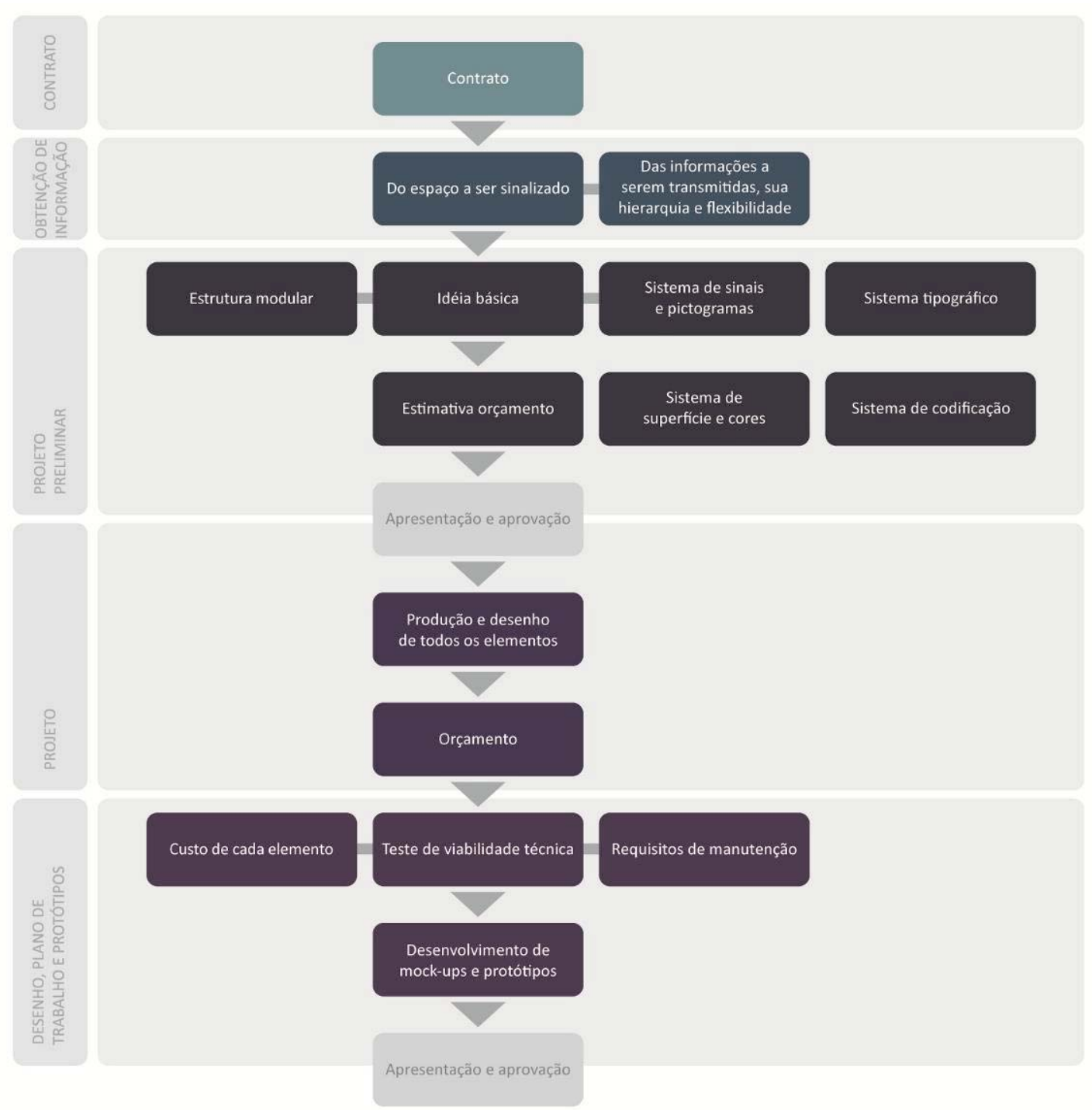


Figura 3b: Metodologia de Uebele. Fonte: Adaptado de Uebele (2007). Continuação do esquema anterior.

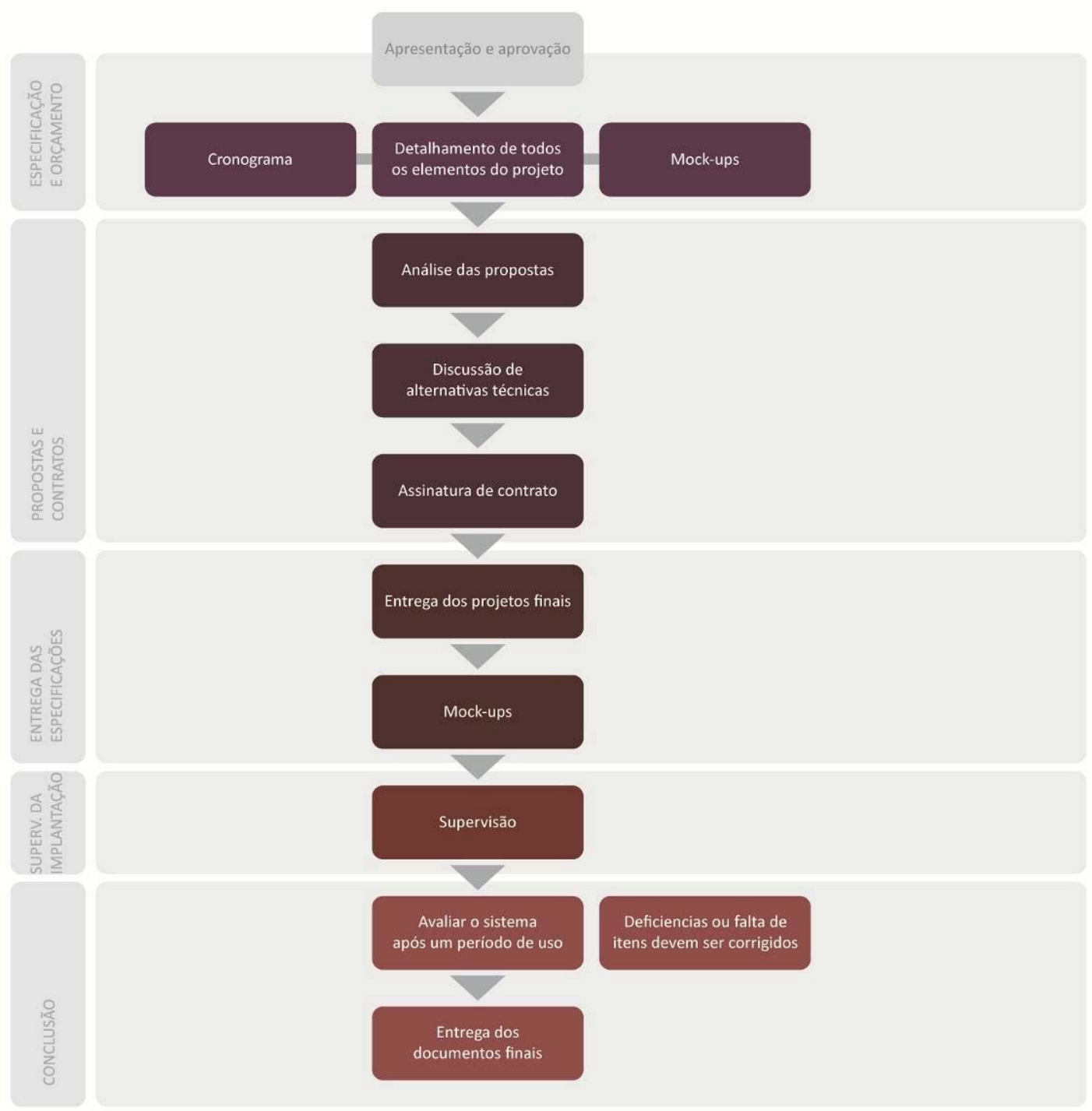

Chris Calori (2007), no livro Signage and Wayfinding Design, desenvolveu um método similar ao utilizado em projetos arquitetônicos. Destaca a autora que o método ainda é útil para "educar" o cliente sobre o processo de evolução de um projeto em design e as alternativas de soluções são geradas, desenvolvidas e implementadas. A autora apresenta o processo de projeto em três grandes grupos: I. Pré-Design; II. Design; III. Pós-Design e salienta que, diferente dos projetos convencionais de design gráfico, seja para mídia impressa ou digital, o projeto de sinalização comumente leva meses e pode levar até mesmo anos para estar completo.

De maneira linear, a autora divide o processo em sete as fases de projeto, porém destacando que mesmo apresentadas como fases distintas e linearmente em ordem, elas podem, muitas vezes, se confundir ou retroceder (figuras 4a e 4b). São elas: 1 - Levantamento e análise de dados; 2 - Desenho esquemático; 3 - Desenvolvimento; 4 - Documentação; 5 Contratação de fornecedores; 6 - Fabricação, instalação e acompanhamento; 7 - Avaliação pós-instalação.

Em uma análise de acordo com os critérios de avaliação colocados anteriormente, tem-se (i) atitude metodológica prescritiva, (ii) estrutura linear dividida em 7 etapas, (iii) flexibilidade das etapas descontínua, pois mesmo apresentada linearmente, deixa claro que pode haver descontinuidade; e (iv) presença de feedback de acordo com as aprovações intermediárias e final. A avaliação final do projeto implantado (cliente e usuários) e aprovação pelo cliente implicam também em feedback final. Quanto aos aspectos em particular, não apresenta o 
emprego da nomenclatura "manual", porém sistematiza o projeto completo na fase de documentação, e faz uso de modelos físicos e virtuais na etapa de desenvolvimento.

Figura 4a: Fases do projeto em sinalização. Fonte: Adaptado de Calori (2007).

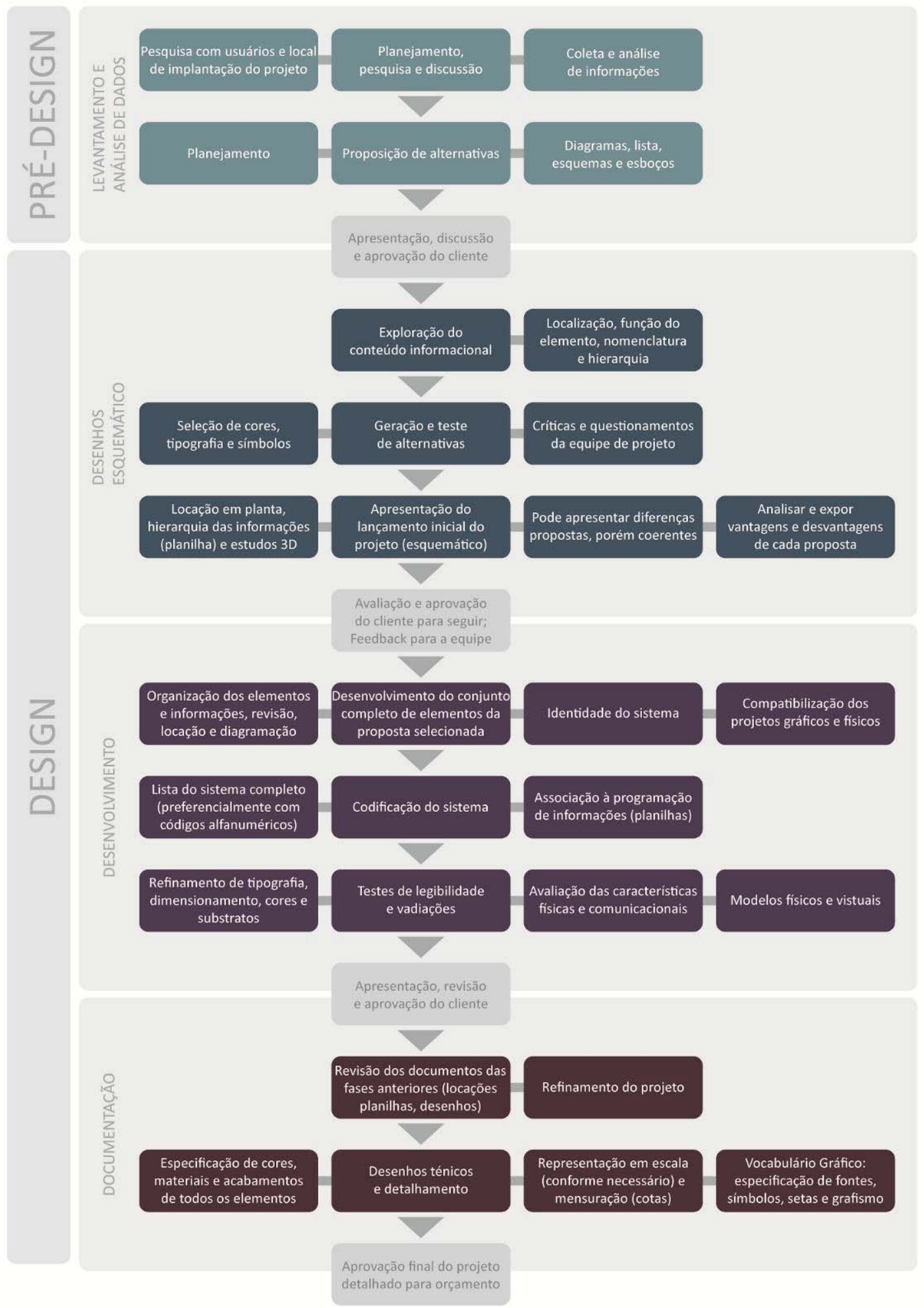




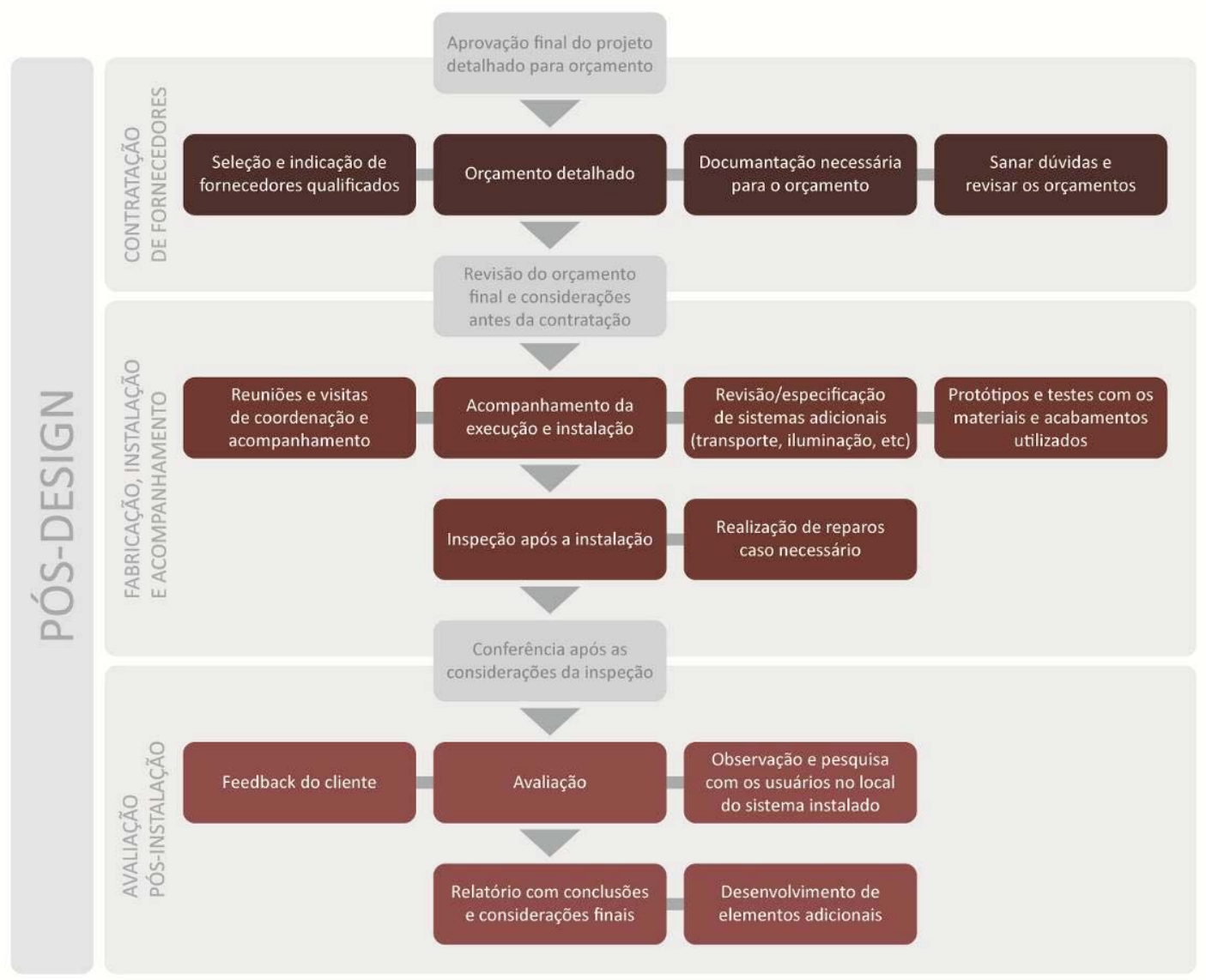

Para Smitshuijzen (2007), a metodologia básica para projetos de sinalização deve seguir os mesmos princípios que são aplicados em métodos de orientação no ambiente em projetos arquitetônicos. Desta forma, a gama de diferentes itens, extremamente relacionados, torna o trabalho de projeto em sinalização muito complexo e desta forma a metodologia empregada é muito importante, sendo um fator primordial para alcançar bons resultados.

Smitshuijzen (2007) destaca ainda que o objetivo do projeto de um sistema de sinalização é criar as melhores condições para "navegação" e orientabilidade para o usuário. Assim, deve fornecer todas as instruções obrigatórias e complementares para fins de segurança e criar oportunidades para transmitir informações gerais sobre a marca ou local do sistema.

Sua proposta identifica seis fases básicas (figuras $5 \mathrm{a}$ e $5 \mathrm{~b}$ ) para o desenvolvimento dos projetos de sinalização: 1: planejamento; 2: criação e desenho do sistema de sinalização; 3 : design visual; 4: documentação e contratação de fornecedores; 5: supervisão; 6 : avaliação e elaboração do manual. Porém, para projetos maiores, o autor destaca que as duas primeiras fases podem ser desmembradas em mais partes. Assim como salienta que design não é apenas um exercício ou experiência de estilo ou puramente visual, é também o desenvolvimento de idéias para encontrar soluções novas e adequadas dentro dos limites e restrições dadas. Este tipo de desenvolvimento do projeto só pode ser baseado em uma profunda compreensão do problema de projeto em todos os seus aspectos.

De acordo com os critérios de avaliação anteriormente citados, tem-se (i) atitude metodológica prescritiva, (ii) estrutura linear dividida em 6 etapas, (iii) flexibilidade descontínua entre etapas, uma vez que depende de aprovação; e (iv) presença de feedback visto a possibilidade de descontinuidade entre as etapas. A avaliação final do projeto implantado e aprovação pelo cliente implicam também em feedback final. Quanto aos aspectos em particular, apresenta o emprego de manual do sistema de sinalização e utilização de modelos virtuais e físicos. Apresenta ainda a situação de complementação do sistema e alteração para manutenção futura após a avaliação final. 
Figura 5a: Metodologia de Smitshuijzen. Fonte: Adaptado de Smitshuijzen (2007).

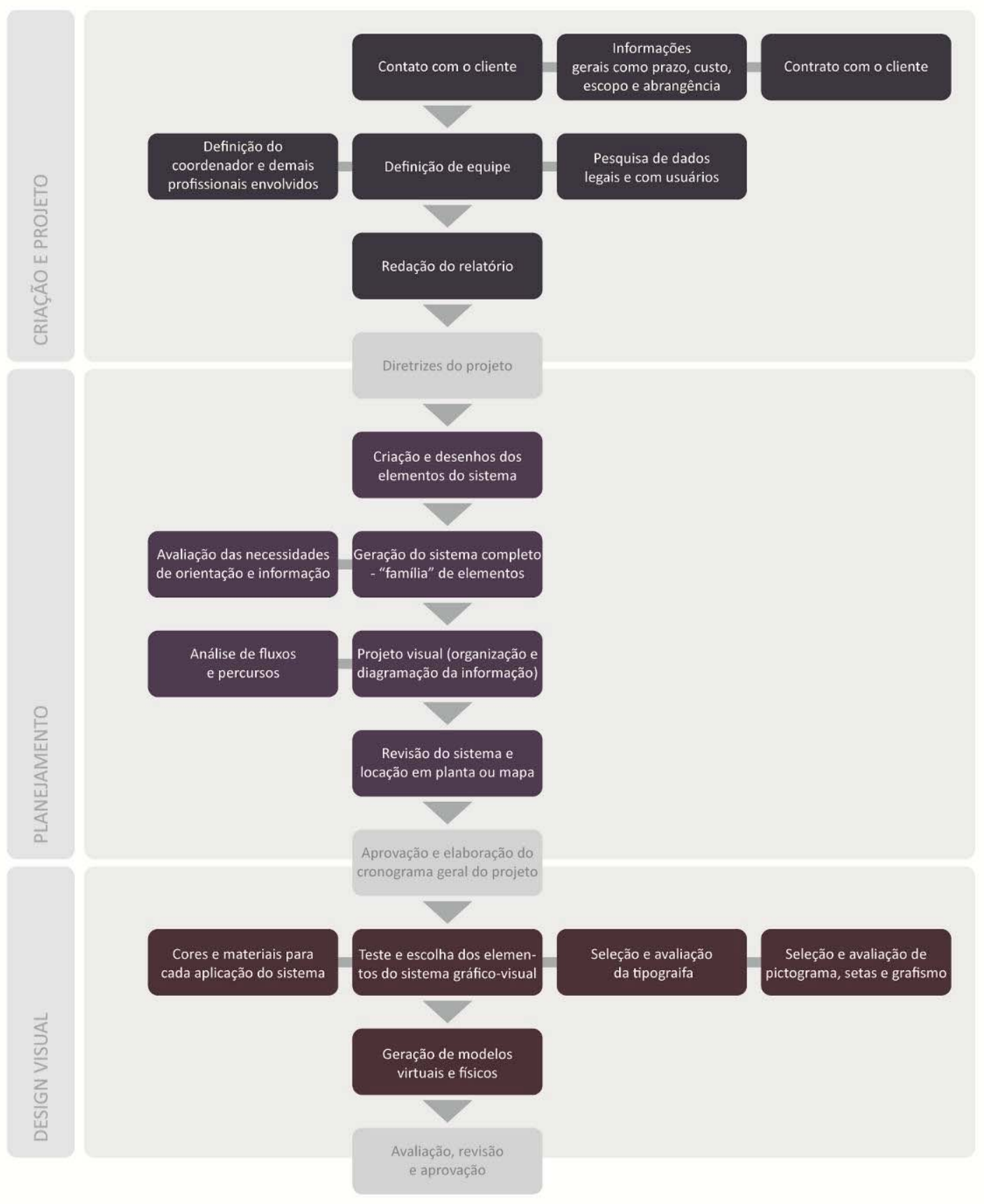




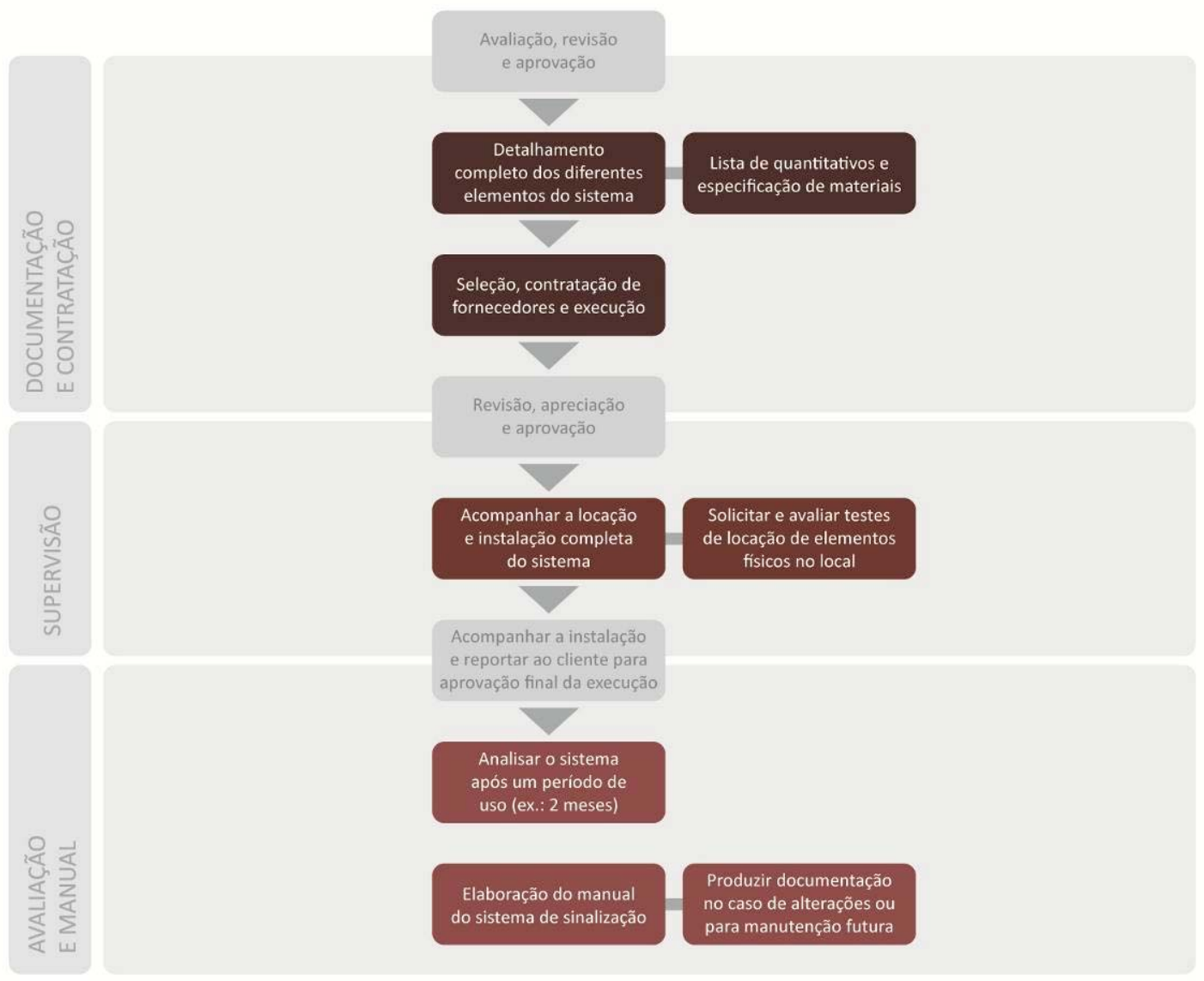

A reedição do clássico livro Señalética de Joan Costa (2009), originalmente publicado em 1989, traz uma rica pesquisa na história do ato de sinalizar e fornece informações que esclarecem o vocabulário, além de apresentar sua metodologia para condução dos projetos de sinalização.

Segundo Costa (2009), cada projeto de sinalização é diferente e não existem dois iguais, pois as variáveis são diversas. Podem-se classificar estas variáveis em três grandes áreas de atividades: arquitetura (volume, morfologia, estilo, complexidade estrutural do lugar); serviço (objetivos, logística, distribuição do espaço, complexidade funcional) e design gráfico (informação, orientação visual, identidade, serviço: simplicidade de uso). Todos os conjuntos de elementos que se incluem nestes três âmbitos os fazem interdependentes e assim constituem um sistema integrado. Ainda de acordo com o autor, na prática, todo projeto de sinalização é um processo e, como tal, implica em um modo de proceder que busca a articulação entre suas diversas partes. Visto da perspectiva do design gráfico, este processo é claramente distinto do que projetar um cartaz, uma identidade, uma embalagem ou uma página da web. Estas diferenças dizem respeito à escala e, conseqüentemente, as dimensões (implicadas do entorno arquitetônico), a orientação do usuário e a intencionalidade comunicativa. Estas quatro circunstâncias ligadas à percepção das mensagens que integram a informação da sinalização já põem em evidencia a necessidade de uma metodologia específica.

Etimologicamente, um método é um caminho até um objetivo. Projetar não é somente conceber uma idéia, tomar uma iniciativa ou iniciar uma ação com um fim. É também escolher criteriosamente uma via entre outras possíveis, organizar os passos e os tempos, e segui-los até chegar ao objetivo. Dispor de um método é dispor de critérios que permitem em cada etapa optar pelo melhor caminho, aquele que deve que deve levar o mais diretamente possível a solução do problema. Todo método é simultaneamente um procedimento intelectual (aspecto semântico, cognitivo, criativo) e um procedimento operacional (aspecto técnico, pragmático, material) que objetiva um resultado que se determinou antes com a máxima precisão possível (COSTA, 2009). 
Dado que cada caso é diferente e cada problema de sinalização possui uma infinidade de variáveis, optou-se por tomar como modelo um "caso médio". O processo ocorre conforme as seguintes fases: 1: coleta de informações; 2: concepção do sistema; 3: sistema de sinais ou código base; 4: design gráfico; 5: fichas técnicas para produção; 6: supervisão e implementação (figuras 6a e 6b).

De acordo com os critérios de avaliação citados, tem-se (i) atitude metodológica prescritiva, (ii) estrutura linear dividida em 6 etapas, (iii) flexibilidade das etapas contínua; e (iv) não apresenta a presença de feedback entre as etapas, porém a avaliação do projeto implantado prevê correções, sendo assim um tipo de feedback final. Quanto aos aspectos em particular, apresenta o emprego de manual do sistema de sinalização e execução de protótipos em sua última fase, para validação no local.

Figura 6a: Metodologia de Costa. Fonte: Adaptado de Costa (2009).

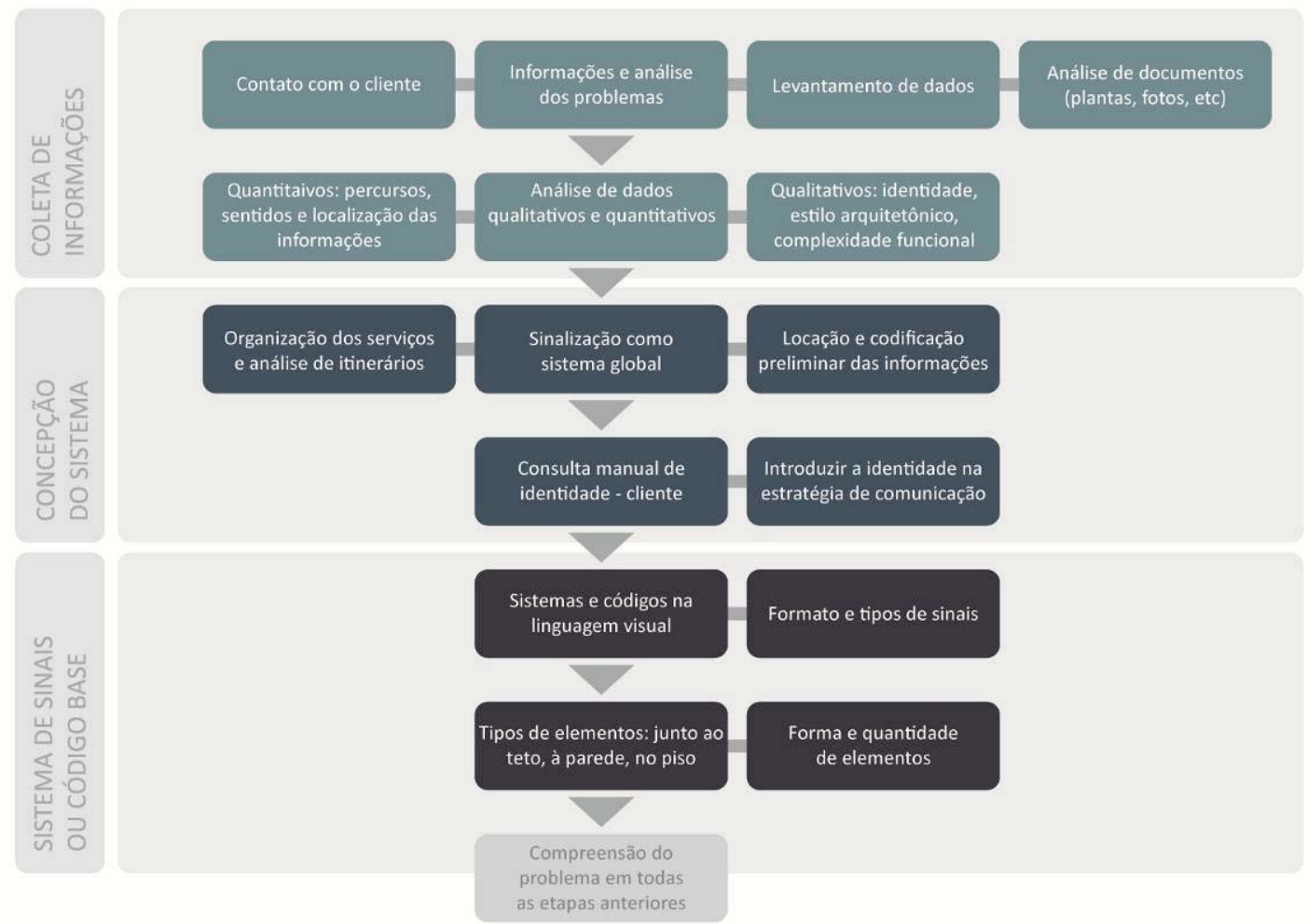


Figura 6a: Metodologia de Costa. Fonte: Adaptado de Costa (2009). Continuação do esquema anterior.

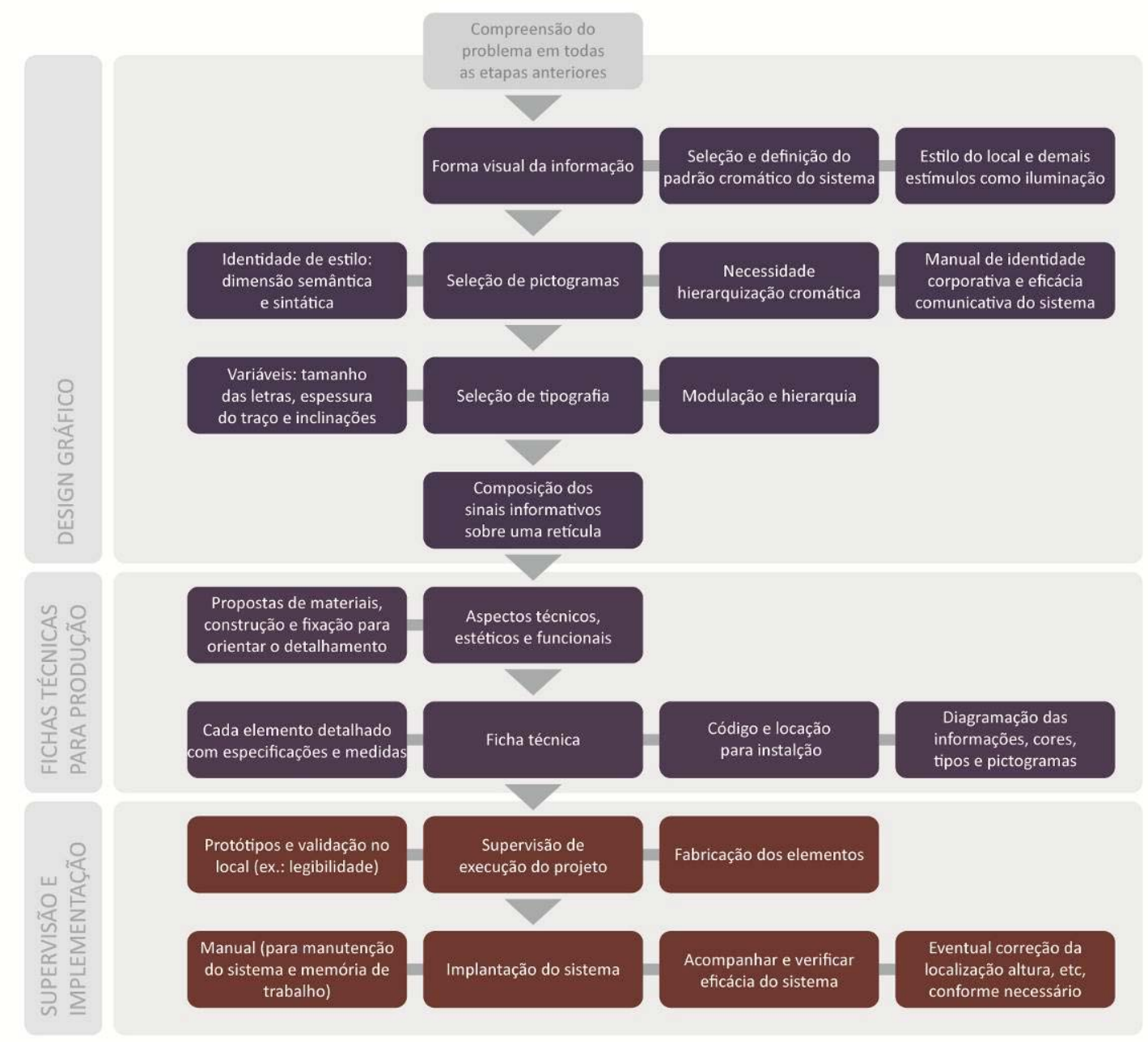

Segundo Gibson (2009), cada projeto de sinalização tem objetivos únicos assim como exigências técnicas e funcionais distintas. Há, no entanto, etapas no processo que são comuns a todos os projetos. O esquema gráfico (figura 07) fornece um modelo geral de como a maioria dos projetos de "wayfinding" procedem. Em projetos menores algumas etapas são, por vezes, combinadas ou mesmo eliminadas. Outras vezes, algumas etapas de um trabalho têm que ser executadas simultaneamente para acomodar um cronograma corrido. Para projetos de longo prazo, pode haver pausas entre as fases, esperando que os demais profissionais envolvidos na execução da obra - arquitetos e engenheiros, por exemplo, concluam seus trabalhos para que o processo possa continuar.

Baseado em Gibson (2009) pode-se dividir o processo de design em três grandes e sequênciais grupos, que por sua vez, podem ser subdivididas em fases (figura 7): Planejamento (Pesquisa e análise, Estratégia e Programação); Design (Desenho esquemático, Desenvolvimento e Documentação de fabricação (projeto executivo)); e Implementação (Suporte à orçamentação e Execução).

De acordo com os critérios de avaliação citados, tem-se (i) atitude metodológica prescritiva, (ii) estrutura linear dividida em 8 etapas, (iii) flexibilidade das etapas descontínua em função de que em projetos menores algumas etapas podem ser combinadas ou mesmo eliminadas; e (iv) não há presença de feedback entre as etapas intermediárias do processo, havendo apenas revisão na etapa final, antes da execução do projeto. A inspeção e avaliação do projeto implantado não prevêem feedback, somente revisão e adequações finais. Quanto aos aspectos em particular, não apresenta o emprego do termo "manual" e sim do termo "memoriais descritivos", onde explicita as intenções de projeto. O autor não deixa claro se há a execução de protótipos de forma sistematizada no processo. 
Figura 7: Metodologia de Gibson. Fonte: Adaptado de Gibson (2009).

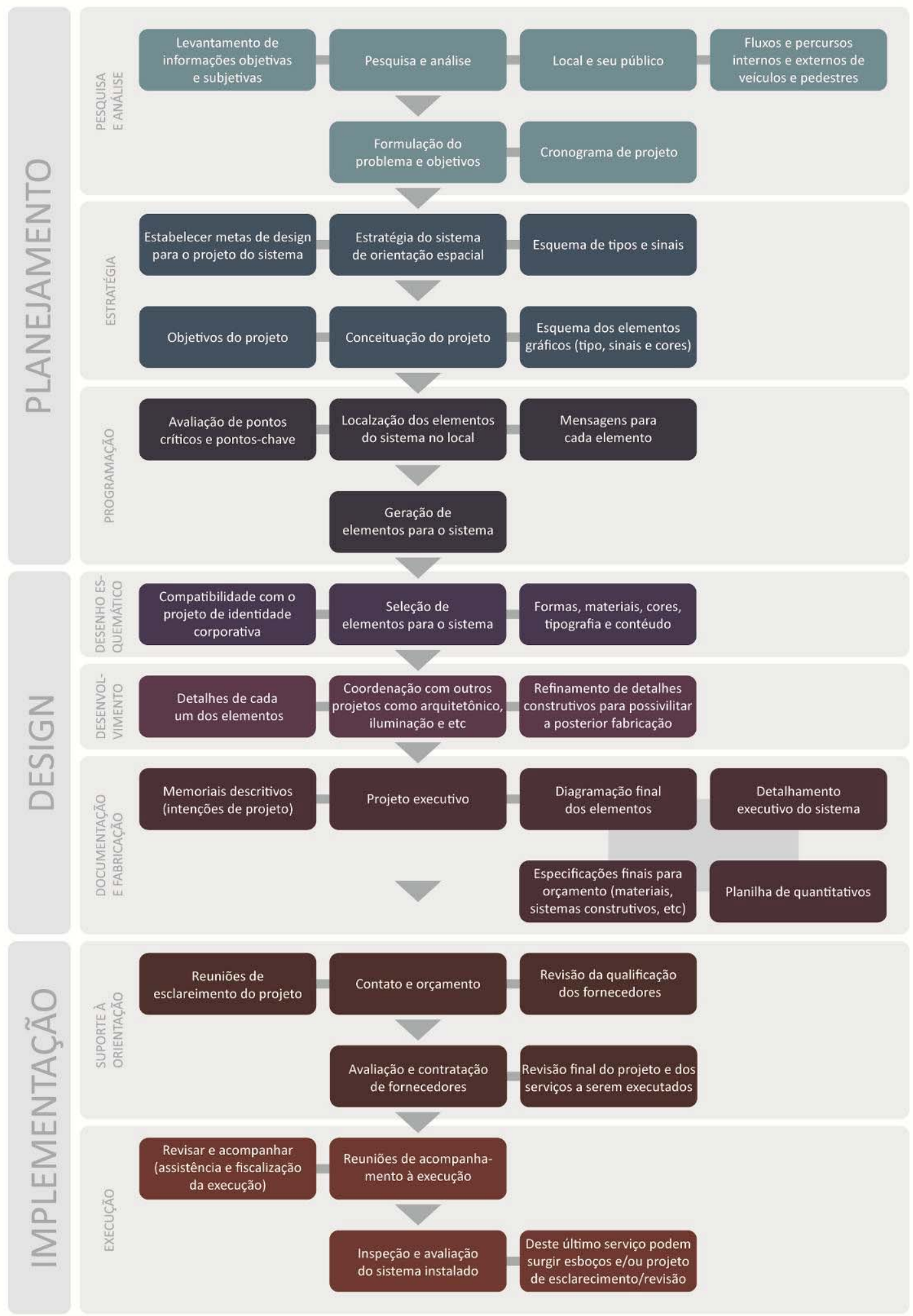

Ao analisar as metodologias apresentadas, têm-se uma visão geral do processo conforme cada autor. Não obstante, é possível identificar tendências de tais esquemas quanto às classificações propostas, que possivelmente demonstram o melhor caminho a ser seguido no desenvolvimento de métodos e processos de design.

Como os métodos de projeto na área de sinalização derivam de áreas em que a sistematização do projeto encontra-se consolidada, e que, de certa forma, deram origem ao 
campo do design gráfico ambiental, como arquitetura, design de produto e design gráfico, é natural que as metodologias apresentadas aqui contenham questões ligadas a estes campos do conhecimento. Assim, pode-se notar que com o passar dos anos, os processos e métodos em design foram aprimorando-se, ao apresentar metodologias de esquemas prescritivos e mais maleáveis, adaptados aos problemas atuais, possibilitando vários retornos e apresentando fases mais detalhadas com técnicas diversas e multidisciplinares aplicadas ao processo.

É importante ressaltar que o método proposto por Follis e Hammer (1979) já trazia tais questões. Nas proposições da última década, apesar das metodologias de Costa (2009) e Gibson (2009) divergirem da maioria, ao não mencionarem claramente as questões de feedback, por exemplo, observa-se o desenvolvimento de modelos essencialmente prescritivos, onde grupos que estruturam fases e etapas flexíveis ganharam espaço, com testes e verificações constantes em cada fase.

Este trabalho passa agora a apresentar a proposição de um método de projeto de sinalização, que leva em consideração as análises acima dispostas, a prática profissional (acadêmica e de mercado), e também outros autores reconhecidos na área de metodologia em design como Back et al (2008).

Dentre a bibliografia apresentada, de acordo com alguns autores como: Calori (2007) e Gibson (2009), nota-se a presença de grandes grupos bem definidos, tais como pré-design ou planejamento; design; e pós-design ou implementação. No decorrer desses grupos são desenvolvidas outras fases e etapas que completam o escopo de trabalho necessário para conclusão de uma fase e o início da próxima. O método proposto neste trabalho foi, então, dividido em três grandes grupos: planejamento, projeto e implementação. Na seqüência, esses grupos foram divididos em fases e estas subdivididas em etapas, conforme as figuras $8 \mathrm{a}$ e $8 \mathrm{~b}$. 
Figura 8a: Fases e etapas do processo de projeto em sinalização.

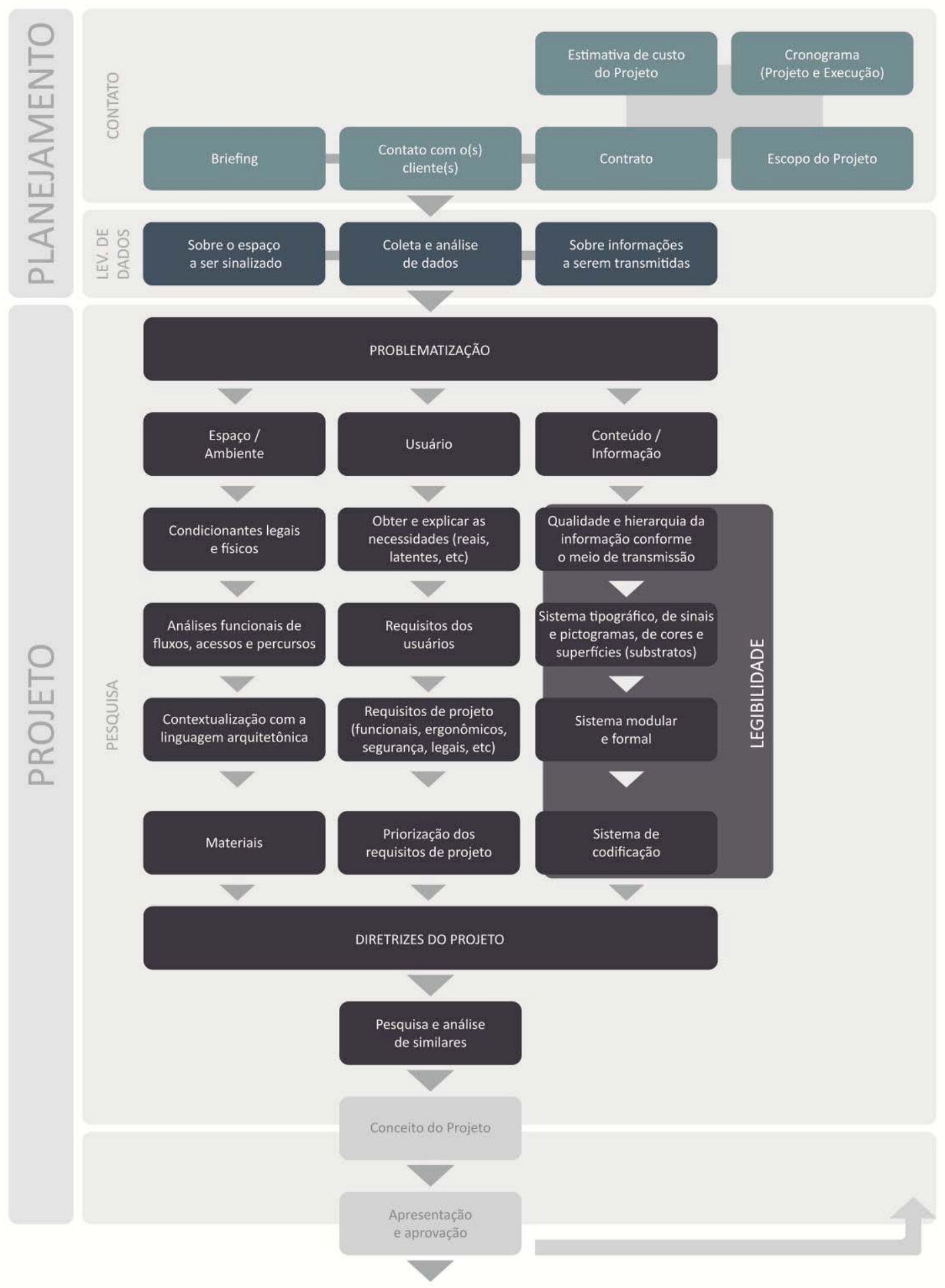


Figura 8b: Fases e etapas do processo de projeto em sinalização. Continuação do esquema anterior.

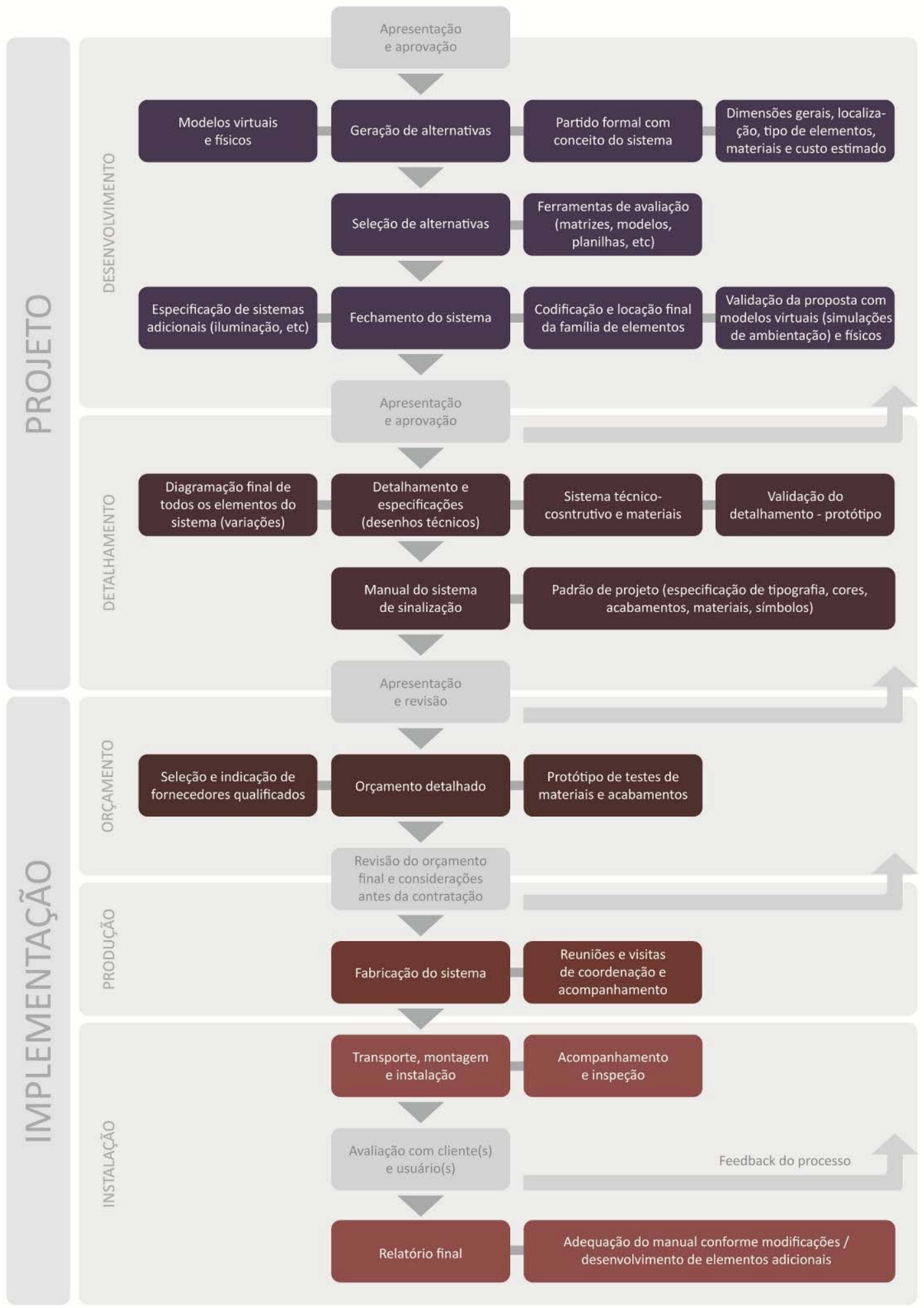

É importante salientar a presença constante entre as etapas de aprovações e feedbacks. Esta flexibilidade permite retornar a etapas anteriores sempre que algo for detectado como errado ou não suficiente, ou quando ocorre a necessidade de inserção de um novo elemento no processo. Após a avaliação com cliente e usuário, parte-se para o relatório final onde devem constar as alterações feitas no manual e a inclusão de elementos adicionais, se for o caso. A existência de um feedback final, ou seja, a avaliação com cliente e usuário, permite sanar inconsistências assim como possibilita aprendizados para novos projetos. 


\section{Considerações finais}

Com base no estudo das diferentes conceituações e das diferentes metodologias empregadas em projetos de sinalização, pode-se encontrar diretrizes através de grupos, fases e etapas recorrentes e complementares. Em muitas referências há, ainda, a possibilidade de feedback e, assim pode-se formular um método que busca ser ao mesmo tempo abrangente e específico. Abrangente ao trabalhar a complexidade da reunião de diferentes contextos - o espaço/ ambiente, a informação e o usuário. Abrangente também por abarcar projetos de pequeno a grande porte, como hospitais, por exemplo, e seus desdobramentos, tais como contratações, orçamentos e licitações. E, específico ao tratar de aspectos particulares do projeto de sinalização, tais como: manual; simulações virtuais; mock-ups; e protótipos.

Como sugestão para continuidade deste estudo vê-se a necessidade de examinar a aplicação prática desse método para validação do mesmo. Coloca-se também a necessidade do desenvolvimento de ferramentas para a avaliação e validação de alternativas, de forma embasada e sistemática.

\section{Referências}

ADG ASSOCIAÇÃO DOS DESIGNERS GRÁFICOS (Brasil). 2000. ABC da ADG: glossário de termos e verbetes utilizados em design gráfico. São Paulo: ADG.

ARTHUR, P.; Passani, R. 1992. Wayfinding People, Signs, and Architecture. New York: McGraw-Hill.

BACK, N. et al. 2008. Projeto Integrado de Produtos: planejamento, concepção e modelagem. São Paulo: Manole.

BASTOS, R. S. 2004. Sinalização: a Comunicação Visual a serviço da identidade e dos ambientes. In: MAGALHÃES, Eliane et al. (orgs.). Pensando Design. Porto Alegre: UniRitter Ed.

BERGER, C. M. 2005. Wayfinding: Design and Implementing Graphic Navigational Systems. Mies (Suíça): RotoVision.

BONSIEPE, G; KELLNER, P; POESSNECKER, H. 1984. Metodologia experimental: desenho industrial. Brasília: CNPq/Coordenação editorial.

CALORI, C. 2007. Signage and Wayfinding Design: A Complete Guide to Creating Environmental Graphic Design Systems. Hoboken: Wiley, 2007.

COSTA, Joan. 2007. Señalética Corporativa. Barcelona: Costa Punto Com.

CROSBY, T.; FLETCHER, A.; FORBES, C. 1970. A Sign Systems Manual. New York: Praeger.

FOLLIS, J.; HAMMER, D. 1979. Architectural Signing and Graphics. New York: Whitney Library of Design.

GIBSON, D. 2009. The Wayfinding Handbook. New York: Princeton Architectural Press.

HUNT, W. 2003. Environmental Graphics: Projects \& Process. New York: Harper Collins.

LYNCH, K. 1997. A Imagem da Cidade. São Paulo: Martins Fontes.

LÖBACH, B. 2001. Design Industrial: Bases para configuração dos produtos industriais. Rio de Janeiro: Edgard Blücher.

MOLLERUP, P. 2005. Wayshowing: A Guide to Environmental Signage Principles and Practices. Baden, Suíça: Lars Müller.

SEGD - SOCIETY FOR ENVIRONMENTAL GRAPHIC DESIGN. Disponível em http://www.segd.org/home.html\#/home.html <Acessado em 18/01/2011>

SMITSHUIJZEN, E. 2007. Signage Design Manual. Baden, Suíça: Lars Müller.

UEBELE, A. 2007. Signage System \& Information Graphics. London: Thames \& Hudson.

VASCONCELOS, Luis; et al. 2010. Um Modelo de Classificação para Metodologias de Design. In 9॰ Congresso Brasileiro de Pesquisa e Desenvolvimento em Design. São Paulo. 
VELHO, A. L. de O. L. 2007. O Design de Sinalização no Brasil: a introdução de novos conceitos de 1970 a 2000. Dissertação (Mestrado). PUC-Rio, Rio de Janeiro.

\section{Sobre os autores}

Eduardo Cardoso, Me. UFRGS. Professor Assistente do Departamento de Design e Expressão Gráfica da Faculdade de Arquitetura da Universidade Federal do Rio Grande do Sul. Arquiteto e Urbanista - Unisinos. Tem Mestrado em Design - UFRGS. Atua na área de acessibilidade em design de exposição e sinalização.

eduardo.cardoso@ufrgs.br

Fabiano de Vargas Scherer, Me. UFRGS. Professor Assistente do Departamento de Design e Expressão Gráfica da Faculdade de Arquitetura da Universidade Federal do Rio Grande do Sul. Arquiteto e Urbanista - UFRGS. Tem Mestrado em Planejamento Urbano e Regional - UFRGS. Atua nas áreas de design de informação e metodologia de projeto em design gráfico ambiental (ambientação e sinalização).

fabiano.scherer@ufrgs.br

Fábio Gonçalves Teixeira, Dr. UFRGS. Professor Associado do Departamento de Design e Expressão Gráfica da Faculdade de Arquitetura da Universidade Federal do Rio Grande do Sul. Coordenador do Programa de Pós-Graduação em Design - UFRGS. Tem Mestrado em Engenharia Civil e Doutorado em Engenharia Mecânica - UFRGS e Pós-doutorado na Universidade do Porto.

fabiogt@ufrgs.br

Régio Pierre da Silva, Dr. UFRGS. Professor Adjunto do Departamento de Design e Expressão Gráfica da Faculdade de Arquitetura da Universidade Federal do Rio Grande do Sul. Professor Permanente do Programa de Pós-Graduação em Design - UFRGS. Tem Mestrado em Engenharia de Produção e Doutorado em Engenharia de Produção - UFSC. Atua nas áreas de design instrucional e projeto de produto.

régio@ufrgs.br

Tânia Luisa Koltermann da Silva, Dra. UFRGS. Professora Adjunto do Departamento de Design e Expressão Gráfica da Faculdade de Arquitetura da Universidade Federal do Rio Grande do Sul. Professora Permanente do Programa de Pós-Graduação em Design - PGDESIGN UFRGS. Tem Mestrado e Doutorado em Engenharia de Produção - UFSC. Atua nas áreas de design de produto digitais, design instrucional e projeto de produto.

tania.koltermann@ufrgs.br 